\title{
An ectodermal dysplasia patient treated with a small diameter implant supporting a single crown
}

This article was published in the following Dove Press journal:

Clinical, Cosmetic and Investigational Dentistry

\section{Andrea Mascolo,' \\ Elio Boschetti,' \\ Dennis Flanagan ${ }^{2}$}

'European Institute for Medical Studies, H.E.I. Graduate School, Malta; ${ }^{2}$ Private Practice, Willimantic, CT, USA
Correspondence: Dennis Flanagan Main St Willimantic, Willimantic, CT 06226, USA

Email dffdds@comcast.net

\begin{abstract}
Ectodermal dysplasia (EDD) is a developmental disorder that affects the skin, hair, and teeth among other organs generated in the ectoderm. Dental implants have been used to successfully treat partial edentulism in EDD patients, but the success rate is much lower for these patients. The report herein is a successful case of a single mini, small diameter, implant used to support a single crown of a mandibular right second premolar. A review of implant treatment in EDD patients is included.
\end{abstract}

Keywords: dental implant, mini implant, occlusal, load, osseointegration

\section{Introduction}

Dental implants can be used to successfully restore partial and complete edentulism. There are patients who present with systemic disorders that may affect outcomes. Ectodermal dysplasia (EDD) is one of these. ${ }^{1,2}$ There have been reports on successful dental implant treatment in patients with EDD, but the success rate is much lower for EDD patients. ${ }^{3,4}$ This is a case report of a successful single crown supported by a small diameter, mini, implant in a patient with EDD.

\section{EDD}

EDD is a large group of disorders with developmental abnormalities in ectodermal structures that include skin, hair, nails, teeth, and glands. ${ }^{1,2}$ Among a variety of signs and symptoms of EDD are dry hypoplastic skin, sparse scalp and body hair, dystrophic fingernails, deficient sweat glands, and oligodontia. ${ }^{1,2}$ These patients exhibit two or more affected structures that develop from ectoderm. ${ }^{1,2}$ Teeth affected by EDD is one of the criteria for distinguishing between affected and unaffected individuals in a clinical examination. There are over 120 syndromes in which oligodontia is one of the associated findings. ${ }^{4,5}$ The majority of these are hereditary. The most commonly associated with missing teeth are Down syndrome and EDD. ${ }^{6}$ Oligodontia is defined as the absence of more than six teeth, excluding third molars. ${ }^{2,6-9}$ There are more than 200 types of EDD, but the causative gene is known in only 60 types. $^{7-9}$ This disorder has an incidence of 1:100,000 births and is more common among boys. ${ }^{1,2,7-9}$ The phenotypical outcome is the result of an autosomal dominant, autosomal recessive, or X-linked genetic expression. ${ }^{9-13}$ The most common form is the X-linked, hypohidrotic form and constitutes about $80 \%$ of those affected. ${ }^{14-16}$ Edentulous sites are often hypoplastic with sharp narrow atrophic ridges. ${ }^{17,18}$ Early diagnosis of EDD is essential 
for appropriate treatment. To address all aspects of EDD, multidisciplinary treatment planning may be important from childhood to adulthood. ${ }^{19-26}$

\section{Dental implant treatment of patients with EDD}

The dentition and smile are crucial for the oral function and overall facial esthetics. ${ }^{27,28}$ Generally, patients desire dental treatment for functional and esthetic reasons. Oral rehabilitation of EDD patients in the past has involved partial or complete removable prostheses supported by tissue or teeth. Dental implant-supported prostheses has provided an additional treatment option for these patients. ${ }^{29}$

Wong et al studied the oral health and related quality of life (QL) in patients with EDD. ${ }^{25}$ They targeted young individuals aged 11-15 years. These patients lacked a mean of 8.9 teeth and reported this to have a considerable QL impact. The majority ( $88 \%$ ) reported functional limitations and emotional well-being issues. ${ }^{25}$ Locker et al studied QL in 36 Canadian children who were missing a mean of 6.8 teeth; $75 \%$ reported functional and psychosocial impacts "often" or "every day/almost every day". ${ }^{26}$

Small diameter implants (SDIs) can be considered for the retention of removable dentures and the support of fixed prostheses especially in narrow ridges. Patients treated with SDIs for removable prosthetic retention had more satisfaction with their rehabilitation than those treated with conventional nonimplant-supported prostheses. ${ }^{30}$ The treating clinicians reported better retention, masticatory efficiency, and comfort with a positive impact on their QL. ${ }^{30}$

Some reports in literature described the use of mini implants for prosthetic rehabilitation of children and in children affected by EDD. ${ }^{31-33}$ The early insertion of dental implants is recommended in children with severe hypodontia. ${ }^{34,35}$ Buser et al at an International Team of Oral Implantology Consensus Conference 2000 described EDD as a condition which may affect oral tissues by increasing their susceptibility to other diseases by interfering with healing and increasing the risk of implant failure. ${ }^{36}$ Guckes et al, in a prospective study done on 51 patients with EDD, aged 8-68 years, placed implants in anterior mandibles and anterior maxilla. ${ }^{37}$ The implant survival rates were $91 \%$ in the mandible and $76 \%$ in the maxilla. ${ }^{37} \mathrm{~A}$ literature review by Yap and Klineberg concluded that implant survival rates vary between $88.5 \%$ and 97.6\% in patients with EDD and between $90 \%$ and $100 \%$ in patients with tooth agenesis. ${ }^{38}$ Implants placed in adolescents with EDD do not have a significant effect on craniofacial growth, but there is a higher risk of implant failure..$^{38,39}$

\section{Case report}

A 20-year-old female affected by EDD presented with a chief complaint of a painful, mobile, and carious mandibular right second deciduous molar. Extraoral examination revealed hypotonicity of the perioral musculature. Her hair was thin and sparse. Her skin was dry, prone to rashes and easily sunburned. A medical consultation was made but no genetic testing was obtained on this patient, so a specific diagnosis type could not be made. The oral examination disclosed carious deciduous teeth and oligodontia (Figures 1-3). On the right side, missing permanent teeth were the maxillary second and third molars, second premolar, central and lateral incisors, left premolars, and second and third molars. In the mandible missing teeth were the right third molar, second premolar, left third molar and second premolar, and central incisors. Eleven teeth were absent from agenesis. The mandibular incisors were incompletely developed (Figure 2). Multiple carious deciduous teeth were deemed hopeless (Figures 1 and 2). After a discussion and informed consent was obtained from the patient to have the case details and any accompanying images published, implant treatment was decided upon.

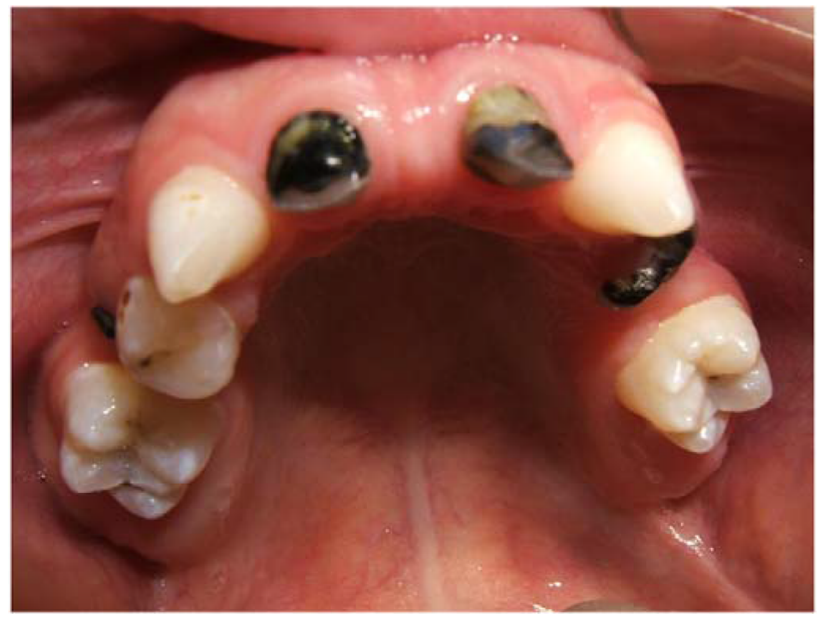

Figure I Maxilla of the ectodermal dysplasia patient.

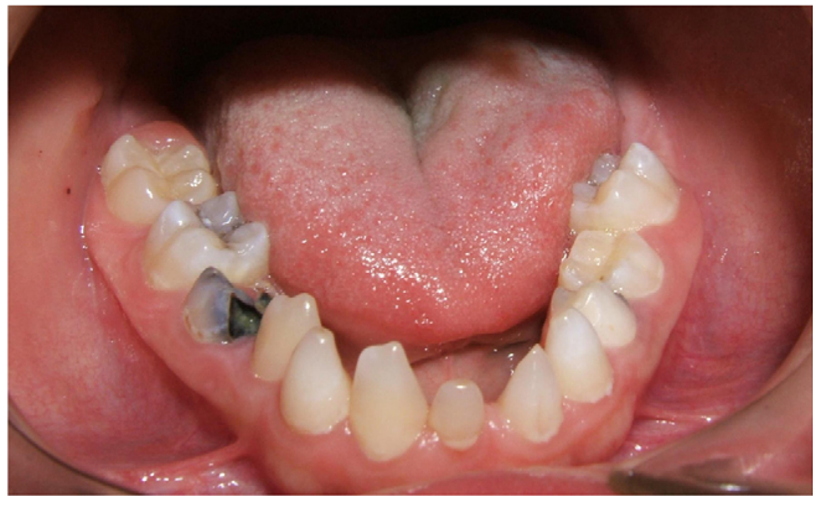

Figure 2 Mandible of the ectodermal dysplasia patient. 


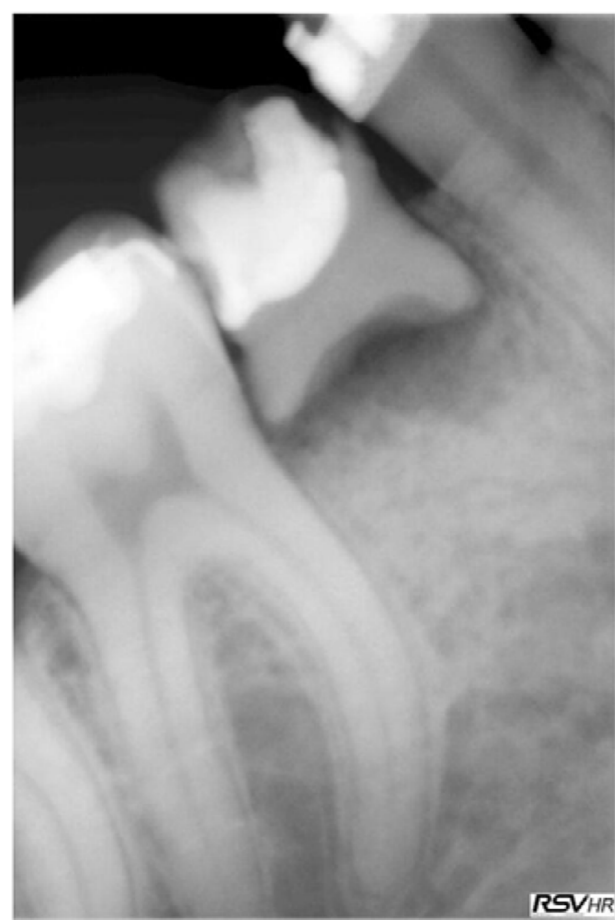

Figure 3 The unrestorable carious and exfoliating mandibular second deciduous molar.

First, carious deciduous teeth were extracted, the maxillary lateral incisors, and right second molar and left first molar and the mandibular right second molar (Figure 4). The maxillary right first premolar was extracted due to coronal caries and radicular malformation. The mandibular left first premolar had a malformed root but was left in place. The mandibular second premolar was absent due to agenesis. The overlying deciduous second molar was slightly submerged. Orthodontic treatment was then instituted over a 7-year period at the Department of Orthodontics, University of Genoa, Italy, without complications (Figures 5 and 6).

A maxillary 12 unit all-ceramic fixed partial denture, from first molar to first molar, was fabricated. This was supported by the first molars and cuspids. Preemptive cuspid endodontics were needed due to large pulp chambers. Endodontic therapy was performed on the maxillary left first molar due to occlusal caries. Implants were not considered because of the high failure rate in EDD patients. Additionally, SDIs may not perform well in the maxilla due to probable low bone density and off-axial loading from the mandibular incisors.

The mandibular right second premolar site had healed well (Figure 7). This implant was planned to be placed flaplessly. A $2.5 \times 13 \mathrm{~mm}$ SDI (MDL Intra-Lock International ${ }^{\circledR}$, Boca Raton, FL, USA) was selected and placed according to SDI guidelines. ${ }^{48}$ An osteotomy was performed with a $1.2 \mathrm{~mm}$ drill

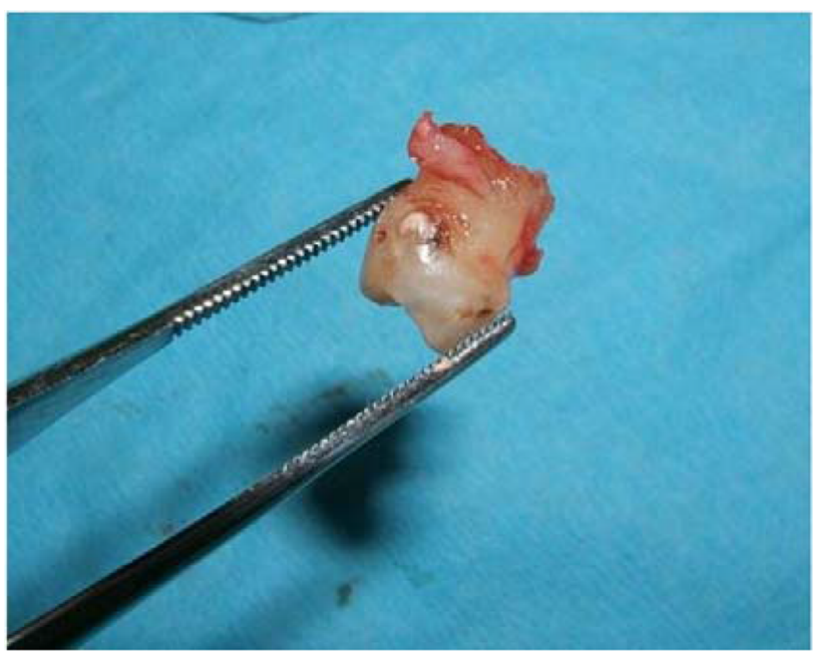

Figure 4 The unrestorable carious and exfoliating mandibular second deciduous molar was extracted.

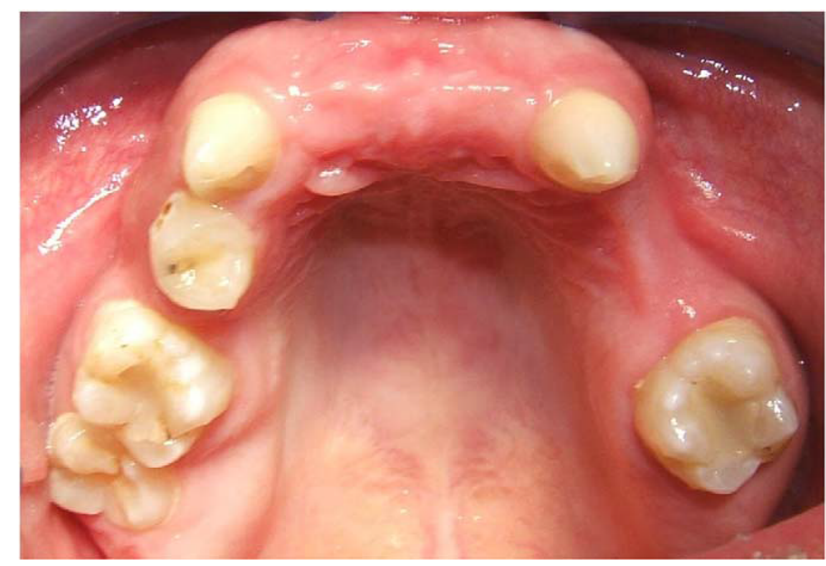

Figure 5 Healing after extractions.

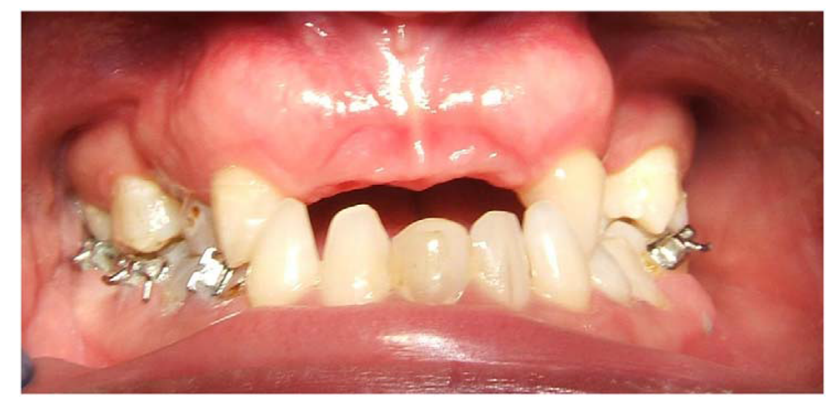

Figure 6 Orthodontic treatment was instituted.

sited equidistantly between the premolar and first molar and the center of the ridge crest. During osteotomy, a qualitative assessment of type 3 bone was made. The implant was then seated at $12 \mathrm{rpm}$ and water cooled to prevent any significant insertion heat (Figures 8-10). An impression was done at insertion appointment and fabricated during the osseointegration time. After 3 months, a low cusp ceramic crown was inserted, 


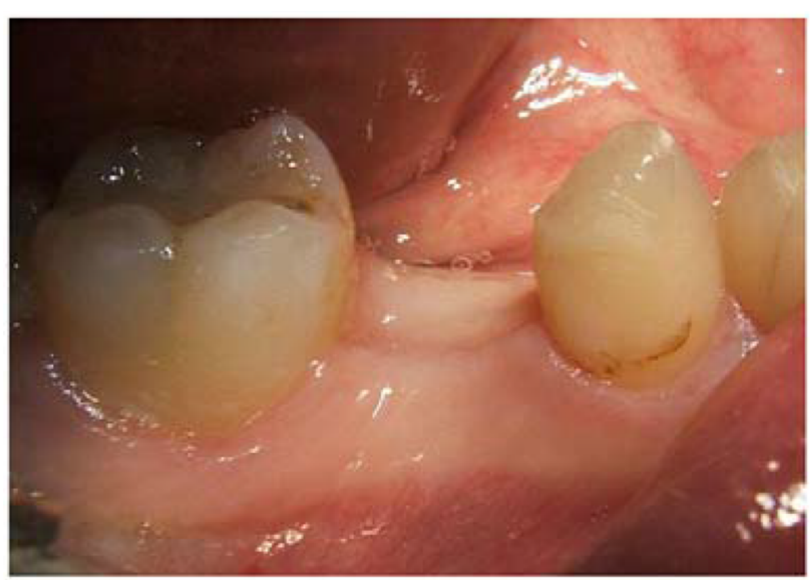

Figure 7 The healed site.

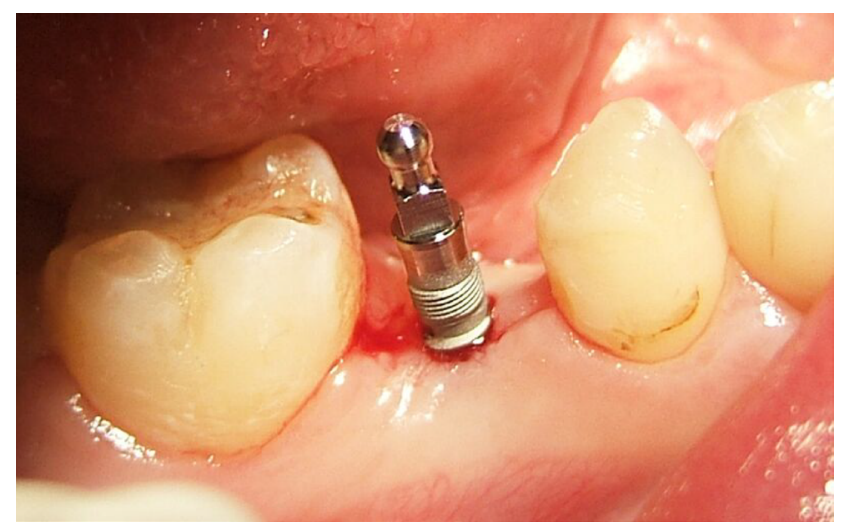

Figure 8 The small diameter implant was placed at 12 rpm and water cooled during seating.

assessed, and definitively cemented with Cement-Over ${ }^{\mathrm{TM}}$ Abutment (Intra-Lock International) (Figures 11 and 12). The crown has been in uneventful successful function for 4 years (Figure 13).

\section{Discussion}

EDD is a rare genetic disorder that is usually transmitted as an X-linked recessive trait. ${ }^{40}$ Ninety-five percent of patients with EDD have the X-linked form. ${ }^{40}$ Because of subtle manifestations, EDD is difficult to diagnose. The number of teeth that develop are a basis of diagnosis. Hypodontia, anodontia, and dental malformations are part of the disorder. Because the teeth give the alveolar ridges osseous stimulation, absence of teeth results in narrow atrophic edentulous ridges that make poor support for removable dentures. ${ }^{40}$ Thus, endosseous implants can provide support and retention for effective function of fixed or removable prostheses. ${ }^{40}$ However, endosseous dental implants should

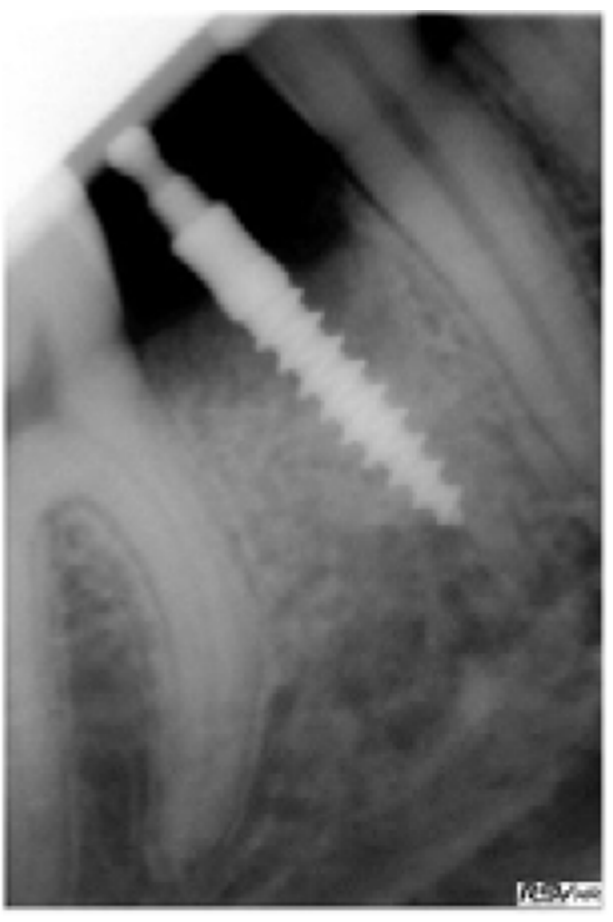

Figure 9 Radiograph during seating of small diameter implant.

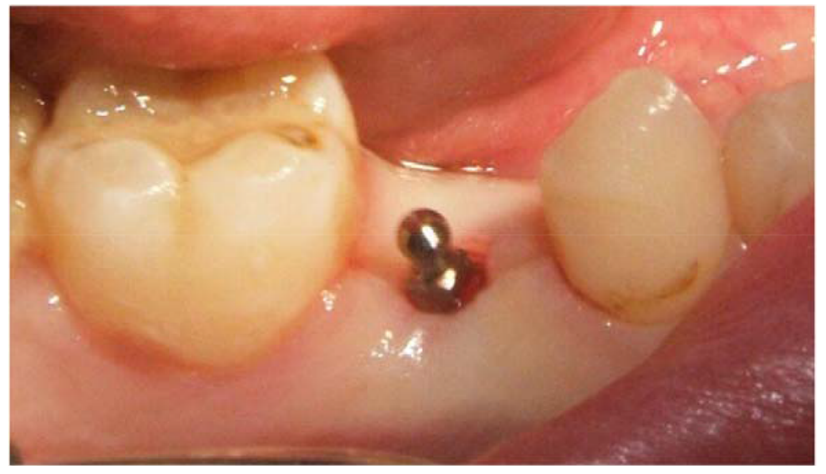

Figure 10 The implant after integration.

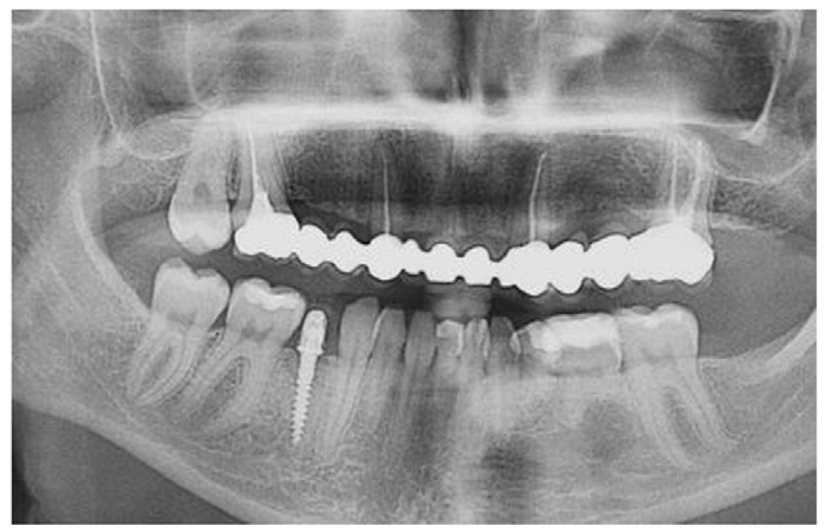

Figure II Panoramic radiograph after treatment completion. 


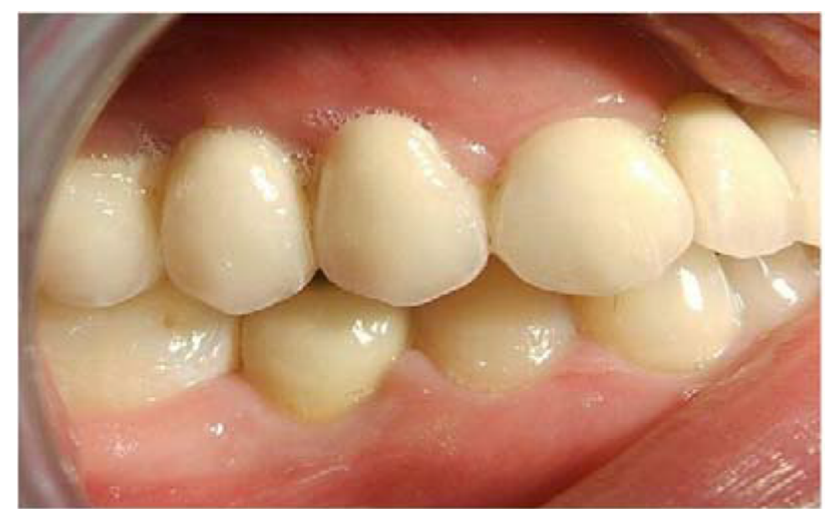

Figure 12 The small diameter implant-supported crown in function.

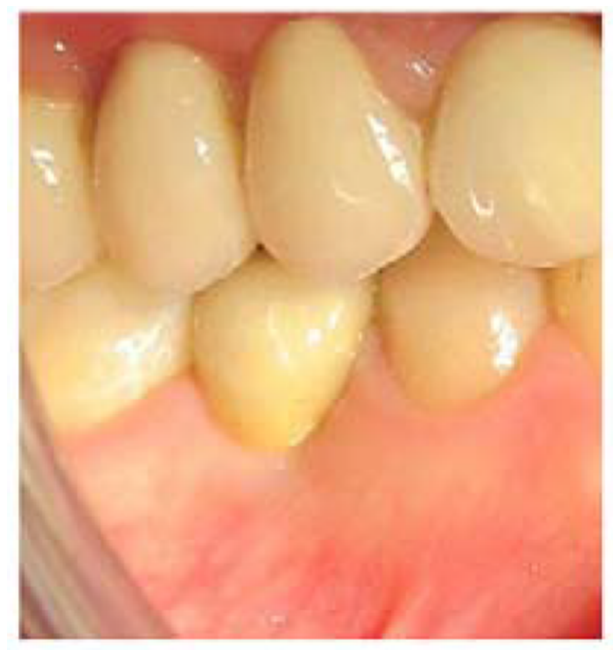

Figure 13 The small diameter implant-supported crown in function after 4 years.

not be placed until skeletal growth is complete. ${ }^{40}$ The implants may stabilize and maintain the osseous ridges. ${ }^{40}$ The goal of treatment is to improve function and provide an esthetic outcome. ${ }^{40}$ Poor alveolar development, a larger number of missing teeth, and the morphology and position of the teeth that did develop complicate the management of treatment. ${ }^{40}$

Patients with hypodontia are frequently treated with complete or partial conventional removable prostheses. ${ }^{41,42}$ In the case described herein, a small diameter implant was selected because of its small displacement. A small physical displacement may be beneficial, in that the implant has a substantial supporting bone volume for remodeling. In case of a failure, there would be less osseous resorption and more remaining bone for a revision. Nonetheless, SDIs exert more osseous load than standard implants. ${ }^{43-45}$ Load attenuation needs to be addressed by an occlusal scheme that minimizes off-axial forces. ${ }^{43,44}$ Additionally, assessing the patients' load generating capability may be an important parameter to assess the risk of overload. ${ }^{43-45}$ An excessive jaw force capability may indicate a larger diameter implant to exert less per-square-mm load on the supporting bone. ${ }^{43-45}$ Although no bite force assessment was made, the qualitative load assessment was deemed to be of low magnitude. After functional loading, the implant showed no marginal bone loss with apparent appropriate bone remodeling at a 4-year follow-up (Figures 11-13).

When there is alveolar ridge resorption, the facial cortex approaches the lingual cortex and narrows the residual ridge. ${ }^{43}$ There is less medullary bone as compared to dense cortical bone. This may enable better support for SDIs because the implant then engages the dense cortical bone throughout its complete length. The dense cortical bone is highly resistant to occlusal loads that are delivered to the bone. ${ }^{43}$

Bergendal demonstrated a $64.3 \%$ implant failure in patients with EDD. ${ }^{23}$ Nonetheless, other reports showed that dental implants can be used successfully in partially and completely edentulous patients affected by congenital disorders, such as EDD. ${ }^{31-33}$ Thus, children and adults with EDD may be treated with SDIs in atrophic ridges due to the residual cortices.

Oral prostheses supported by implants provide comfortable function and psychological benefits for children with EDD. ${ }^{40}$ Sfeir et al affirmed that mini implants can be a part of dental treatment for EDD patients and that their use reduces the number of surgeries. ${ }^{33}$

Literature reports indicate that different cusp inclinations can have a significant effect on bone remodeling responses in terms of bone density and osseous stability. ${ }^{46} \mathrm{~A}$ higher cusp inclination can lead to a higher bone remodeling rate and greater bone-implant interfacial stress. ${ }^{46}$ Degidi et al found functional loading to stimulate bone remodeling at the bone-implant interface. ${ }^{48} \mathrm{~A}$ high percentage of lamellar bone was found in loaded implants. ${ }^{47}$

The low SDI volume of displacement may allow appropriate healing by not physically blocking angiogenesis and osteogenesis, as well as subsequent bone remodeling. ${ }^{48,49}$ Nonetheless, the SDI puts a high load on the embedding bone, and the use of a longer SDI may be required to minimize the risk of osseous overload. ${ }^{43,48,49}$ A low cusp height in the occlusal scheme may also lessen the risk of overload of an SDI. ${ }^{43,46}$

Heat may be generated during seating of SDIs, so water coolant may be used to prevent an inordinate temperature increase that may be detrimental to the bone. ${ }^{50}$ EDD complete edentulism can be successfully treated with CAD-CAM implant-supported overdentures. ${ }^{51} \mathrm{CAD}-\mathrm{CAM}$ prosthetic 
fabrication is a definitive technical advance for accuracy, and occlusal loads may be better controlled. ${ }^{51}$

The small percutaneous exposure of SDIs may dramatically reduce the incidence of peri-implant mucositis and peri-implantitis. ${ }^{44}$ No marginal bone loss was seen with this patient in the postoperative 4 years. Implants may not be appropriate in children who have no complete osseous growth due to drifting and displacement of the bones during maturation. $^{45}$

\section{Conclusions}

SDIs may be a minimally invasive approach for support in fixed prosthetics in selected patients with EDD. Preoperative site evaluation and evaluation of the patient's disorder and an appropriate occlusal scheme that minimizes off-axial loads is required. This is a case report and is of a low credibility level. In the future, a meta-analysis of case reports and case series may elucidate this topic for appropriate treatment of these individuals.

\section{Disclosure}

The authors report no conflicts of interest in this work.

\section{References}

1. Salinas CF, Jorgenson RJ, Wright JT, Digiovanna JJ, Fete MD. 2008 International Conference on Ectodermal Dysplasias Classification: conference report. Am J Med Genet A. 2009;149A(9):1958-1969.

2. Irvine AD. Towards a unified classification of the ectodermal dysplasias: opportunities outweigh challenges. Am J Med Genet A. 2009;149A(9):1970-1972.

3. Worsaae N, Jensen BN, Holm B, Holsko J. Treatment of severe hypodontia-oligodontia--an interdisciplinary concept. Int J Oral Maxillofac Surg. 2007;36(6):473-480.

4. Talo T, Acun Kaya F. The effects of ectodermal dysplasia on periodontal tissues. J Int Dent Med Res. 2009;2(2):53-57.

5. Bani M, Tezkirecioglu AM, Akal N, Tuzuner T. Ectodermal dysplasia with anodontia: a report of two cases. Eur J Dent. 2010;4(2):215-222.

6. Ulm MR, Kratochwil A, Ulm B, Solar P, Aro G, Bernaschek G. Threedimensional ultrasound evaluation of fetal tooth germs. Ultrasound Obstet Gynecol. 1998;12(4):240-243.

7. Itin PH. Rationale and background as basis for a new classification of the ectodermal dysplasias. Am J Med Genet A. 2009;149A(9):1973-1976.

8. Visinoni AF, Lisboa-Costa T, Pagnan NA, Chautard-Freire-Maia EA. Ectodermal dysplasias: clinical and molecular review. Am JMed Genet A. 2009;149A(9):1980-2002.

9. Bergendal B. Oligodontia ectodermal dysplasia--on signs, symptoms, genetics, and outcomes of dental treatment. Swed Dent J Suppl. 2010 (205):7-8.

10. Aydinbelge M, Gumus HO, Sekerci AE, Demetoğlu U, Etoz OA. Implants in children with hypohidrotic ectodermal dysplasia: an alternative approach to esthetic management: case report and review of the literature. Pediatr Dent. 2013;35(5):441-446.

11. Kere J, Srivastava AK, Montonen O, et al. X-linked anhidrotic (hypohidrotic) ectodermal dysplasia is caused by mutation in a novel transmembrane protein. Nat Genet. 1996;13(4):409-416.

12. Ziada H, Holland T. Ectodermal dysplasia: a case report. J Ir Dent Assoc. 1997;43(4):127-129.
13. Sakai VT, Oliveira TM, Pessan JP, Santos CF, Machado MA. Alternative oral rehabilitation of children with hypodontia and conical tooth shape: a clinical report. Quintessence Int. 2006;37(9):725-730.

14. Huang C, Yang Q, Ke T, et al. A novel de novo frame-shift mutation of the EDA gene in a Chinese Han family with hypohidrotic ectodermal dysplasia. J Hum Genet. 2006;51(12):1133-1137.

15. Lexner MO, Bardow A, Hertz JM, Nielsen LISA, Kreiborg S. Anomalies of tooth formation in hypohidrotic ectodermal dysplasia. Int J Paediatr Dent. 2007;17(1):10-18.

16. Gruber J, Kreitzberg G. Ectodermal dysplasia. A seven-year case report. NY State Dent J. 2006;72(6):28-31.

17. Glavina D, Majstorovic M, Lulic-Dukic O, Juric H. Hypohidrotic ectodermal dysplasia: dental features and carrier detection. Coll Anthropol. 2001;25(1):303-310.

18. Freiman A, Borsuk D, Barankin B, Sperber GH, Krafchik B. Dental manifestations of dermatologic conditions. J Am Acad Dermatol. 2009;60(2):289-298.

19. Clauss F, Manière MC, Obry F, et al. Dento-craniofacial phenotypes and underlying molecular mechanisms in hypohidrotic ectodermal dysplasia (HED): a review. J Dent Res. 2008;87(12):1089-1099.

20. Bergendal B, Bergendal T, Hallonsten AL, Koch G, Kurol J, Kvint S. A multidisciplinary approach to oral rehabilitation with osseointegrated implants in children and adolescents with multiple aplasia. Eur J Orthod. 1996;18(2):119-129.

21. Hobson RS, Carter NE, Gillgrass TJ, et al. The interdisciplinary management of hypodontia: the relationship between an interdisciplinary team and the general dental practitioner. Br Dent J. 2003;194(9):479-482.

22. Kotsiomiti E, Kassa D, Kapari D. Oligodontia and associated characteristics: assessment in view of prosthodontic rehabilitation. Eur $J$ Prosthodont Restor Dent. 2007;15(2):55-60.

23. Bergendal B. When should we extract deciduous teeth and place implants in young individuals with tooth agenesis? J Oral Rehabil. 2008;35(Suppl 1): $55-63$.

24. Gotfredsen K, Carlsson GE, Jokstad A, et al. Implants and/or teeth: consensus statements and recommendations. J Oral Rehabil. 2008;35(Suppl 1):2-8.

25. Wong AT, Mcmillan AS, Mcgrath C. Oral health-related quality of life and severe hypodontia. J Oral Rehabil. 2006;33(12):869-873.

26. Locker D, Jokovic A, Prakash P, Tompson B. Oral health-related quality of life of children with oligodontia. Int $J$ Paediatr Dent. 2010;20(1):8-14.

27. Somani A, Newton JT, Dunne S, Gilbert DB. The impact of visible dental decay on social judgements: comparison of the effects of location and extent of lesion. Int Dent J. 2010;60(3):5-8.

28. Havens DC, Mcnamara JA, Sigler LM, Baccetti T. The role of the posed smile in overall facial esthetics. Angle Orthod. 2010;80(2): 322-328.

29. Johnson EL, Roberts MW, Guckes AD, Bailey LJ, Phillips CL, Wright JT. Analysis of craniofacial development in children with hypohidrotic ectodermal dysplasia. Am J Med Genet. 2002;112(4):327-334.

30. Preoteasa E, Marin M, Imre M, Lerner H, Preoteasa CT. Patients' satisfaction with conventional dentures and mini implant anchored overdentures. Rev Med Chir Soc Med Nat Iasi. 2012;116(1):310-316.

31. Güler N, Cildir S, Iseri U, Sandalli N, Dilek O. Hypohidrotic ectodermal dysplasia with bilateral impacted teeth at the coronoid process: a case rehabilitated with mini dental implants. Oral Surg Oral Med Oral Pathol Oral Radiol Endod. 2005;99(5):E34-E38.

32. Giannetti L, Murri dello Diago A, Vecci F, Consolo U. Mini-implants in growing patients: a case report. Pediatr Dent. 2010;32(3):239-244.

33. Sfeir E, Nassif N, Moukarzel C. Use of mini dental implants in ectodermal dysplasia children: follow-up of three cases. Eur J Paediatr Dent. 2014;15(2 Suppl):207-212.

34. Kramer FJ, Baethge C, Tschernitschek H. Implants in children with ectodermal dysplasia: a case report and literature review. Clin Oral Implants Res. 2007;18(1):140-146.

35. Sweeney IP, Ferguson JW, Heggie AA, Lucas JO. Treatment outcomes for adolescent ectodermal dysplasia patients treated with dental implants. Int J Paediatr Dent. 2005;15(4):241-248. 
36. Buser D, von Arx T, Ten Bruggenkate C, Weingart D. Basic surgical principles with ITI implants. Clin Oral Implants Res. 2000;11(Suppl):59-68.

37. Guckes AD, Scurria MS, King TS, Mccarthy GR, Brahim JS. Prospective clinical trial of dental implants in persons with ectodermal dysplasia. J Prosthet Dent. 2002;88(1):21-25.

38. Yap AK, Klineberg I. Dental implants in patients with ectodermal dysplasia and tooth agenesis: a critical review of the literature. Int $J$ Prosthodont. 2009;22(3):268-276.

39. Singer SL, Henry PJ, Liddelow G, Rosenberg I. Long-term follow-up of implant treatment for oligodontia in an actively growing individual: a clinical report. J Prosthet Dent. 2012;108(5):279-285.

40. Knobloch LA, Larsen PE, Saponaro PC, L'Homme-Langlois E. Early implant placement for a patient with ectodermal dysplasia: Thirteen years of clinical care. J Prosthet Dent. 2018;119(5):702-709.

41. Paul ST, Tandon S, Kiran M. Prosthetic rehabilitation of a child with induced anodontia. J Clin Pediatr Dent. 1995;20(1):5-8.

42. Pettit S, Campbell PR. Ectrodactyly-ectodermal dysplasia-clefting syndrome: the oral hygiene management of a patient with EEC. Spec Care Dentist. 2010;30(6):250-254.

43. Bulut E, Guler AU, Sen Tunc E, Telcioglu NT. Oral rehabilitation with endosseous implants in a child with ectodermal dysplasia: a case report. Eur J Paediatr Dent. 2010;11(3):149-152.

44. Flanagan D, Mascolo A. The mini dental implant in fixed and removable prosthetics: a review. J Oral Implantol. 2011;37:123-132.
45. Flanagan D, Ilies H, O’Brien B, Mcmanus A, Larrow B. Jaw bite force measurement device. J Oral Implantol. 2012;38(4):361-364.

46. Flanagan D. Bite force and dental implant treatment: a short review. Med Devices. 2017;10:141-148.

47. Rungsiyakull C, Rungsiyakull P, Li Q, Li W, Swain M. Effects of occlusal inclination and loading on mandibular bone remodeling: a finite element study. Int J Oral Maxillofac Implants. 2011;26(3): 527-537.

48. Degidi M, Scarano A, Piattelli M, Perrotti V, Piattelli A. Bone remodeling in immediately loaded and unloaded titanium dental implants: a histologic and histomorphometric study in humans. J Oral Implantol. 2005;31(1):18-24.

49. Serra G, Morais LS, Elias CN, et al. Sequential bone healing of immediately loaded mini-implants. Am J Orthod Dentofacial Orthop. 2008;134(1):44-52.

50. Flanagan D. Heat generated during seating of dental implant fixtures. J Oral Implantol. 2014;40(2):174-181.

51. Chrcanovic BR. Dental implants in patients with ectodermal dysplasia: A systematic review. J Cranio Maxilloofac Surg. Epub 2018 May 21.

52. Alsayed HD, Alqahtani NM, Alzayer YM, Morton D, Levon JA, Baba NZ. Prosthodontic rehabilitation with monolithic, multichromatic CAD CAM complete overdentures in an adolescent patient with ectodermal dysplasia: A clinical report. J Prosthet Dent. 2018;119(6):873-878.
Clinical, Cosmetic and Investigational Dentistry

\section{Publish your work in this journal}

Clinical, Cosmetic and Investigational Dentistry is an international, peer-reviewed, open access, online journal focusing on the latest clinical and experimental research in dentistry with specific emphasis on cosmetic interventions. Innovative developments in dental materials, techniques and devices that improve outcomes and patient satisfac-

\section{Dovepress}

tion and preference will be highlighted. The manuscript management system is completely online and includes a very quick and fair peerreview system, which is all easy to use. Visit http://www.dovepress. $\mathrm{com} /$ testimonials.php to read real quotes from published authors. 